\title{
Analysis of salivary level Lactobacillus spp. and associated factors as determinants of dental caries amongst primary school children in Harar town, eastern Ethiopia
}

Dawit Ademe ${ }^{1}$, Desalegn Admassu' ${ }^{1}$ and Senthilkumar Balakrishnan ${ }^{2^{*}}$ (D)

\begin{abstract}
Background: Lactobacillus spp. play a major role in the development of dental caries. Although effective methods are known for the prevention and management of dental caries, its prevalence of dental caries is increasing amongst school-age children in Ethiopia. Hence, this study is aimed to determine the association of salivary Lactobacillus spp. level and oral health factors as determinants of dental caries amongst primary school children in Harar town, Eastern Ethiopia.

Methods: A cross-sectional study was conducted amongst primary school children $(n=407)$ using a questionnaire survey, clinical DMFT (decayed, missing, filled tooth number) examination and enumeration of salivary level Lactobacillus spp. Data were analyzed by SPSS (Statistical Package for Social Science software- version 25.0). The odds ratio was used to determine the predictors of the outcome. The data were expressed as mean \pm SD. Statistical significance was defined as a $p$-value of less than 0.05 .

Results: The prevalence of dental caries was found to be $36.9 \%$ amongst primary school children. The mean DMFT value of the participants was $0.95 \pm 1.57$. The dental decay component was the primary observation that accounted for $84.6 \%$ of the DMFT. Almost, $67 \%$ of the saliva culture revealed a significant amount of Lactobacillus spp. count. The mean bacterial count was found to be $14.92 \times 10^{5} \pm 22.92 \times 10^{5}$. Among various parameters analysed for association with dental caries, a number of them show positive associtation, incluing reduction in academic scores in the prevous academic year $(p=0.034)$, grade levels of school children $1-4(p=0.041)$, sweet food consumption habit $(p=0.003)$, absence of daily teeth cleaning habit $(p=0.002)$, absence of toothpaste use $(p=0.001)$, dental ache history $(p=<0.001)$, significant microbial load of salivary Lactobacillus spp. $(p=<0.001)$, acidic $(p=0.028)$ and basic salivary $\mathrm{pH}(p=0.025)$.

Conclusion: A significant salivary Lactobacillus count associated with lower grade level, sweet diet, and poor oral hygiene were found to be the determinant factors for dental caries. Thus, dissemination of oral health information is obligatory to prevent dental caries amongst primary school children in the study area.
\end{abstract}

Keywords: Dental caries, Associated factors, DMFT, Lactobacillus, Schoolchildren

\footnotetext{
* Correspondence: nbsenthilkumar@gmail.com

${ }^{2}$ Department of Medical Microbiology, College of Health and Medical

Sciences, Haramaya University, P.O. Box: 235, Harar, Ethiopia

Full list of author information is available at the end of the article
}

(c) The Author(s). 2020 Open Access This article is distributed under the terms of the Creative Commons Attribution 4.0 International License (http://creativecommons.org/licenses/by/4.0/), which permits unrestricted use, distribution, and reproduction in any medium, provided you give appropriate credit to the original author(s) and the source, provide a link to the Creative Commons license, and indicate if changes were made. The Creative Commons Public Domain Dedication waiver (http://creativecommons.org/publicdomain/zero/1.0/) applies to the data made available in this article, unless otherwise stated. 


\section{Background}

Dental caries is a complex and dynamic process where a multitude of factors initiates and influence the progression of the disease [1]. It has been known throughout history but started to become a significant health problem in industrialized countries in the latter part of the nineteenth century, when new technologies allowed the production of large amounts of refined sugars. Globally prevalence indicates about $60-90 \%$ of children and nearly $100 \%$ of the adult world population is suffering from dental caries $[2,3]$. While WHO reports that untreated caries accounts for $44 \%$ dental problems in 2010 [4], lack of oral hygiene practices is common problem in many developing and developed countries $[5,6]$.

Tooth decay or cavity is a breakdown of teeth due to bacterial activity. It is generally caused by association of multiple microorganisms and improper oral hyegiem practices [7]. Streptococcus mutans and Lactobacillus spp. are the most common pathogens isolated from human dental plaque and are considered as the major etiologic agents of caries. However, there is a central role for S. mutans in the initiation and Lactobacillus spp. in the major progression of dental caries [8]. In addition, risk factors such as host susceptibility [9], age [10], dietary habits [11], socioeconomic and oral hygiene status [12] have been associated with increased incidence of dental caries $[3,13,14]$ in human population.

Dental caries is found to be one of the five health problems of school children followed by respiratory diseases, malnutrition, intestinal parasites, skin, eye and ear diseases [2]. Children spend most of the active hours in schools, therefore, hygeinic leassons at schools are better strategies to educate children about oral health. Oral health appraisal in school might consists of determining the total health status of the child through health histories, teacher and nurse observations, medical screening tests, dental examination, and and basic education on oral hygiene $[1,15]$.

However, the lack of locally accessible data to diagnose and treat caries is the central issue in controlling dental caries. Although dental caries has been affecting the majority of the Ethiopian children, much is unknown about the extents and factors that influencing the occurrence. Therefore, this study was intended to determine the prevalence, association of salivary level Lactobacillus spp. and relevant factors as derteminant for dental caries amongst primary school children. This is the first report that analyse the prevalence and factors associated for dental caries in this region, thus it could serve as a baseline for the regional health bureau, non-governmental organizations, researchers and policy makers for considering the interventions strategies to prevent dental caries in Ethiopia.

\section{Methods}

\section{Study period and locality}

A cross-sectional study was conducted from February 7 to March 14, 2018, in primary schools, Harar town, Eastern Ethiopia. Harar is a capital town of Harari Regional State and it is located $515 \mathrm{~km}$ away from the capital city, Addis Ababa.

\section{Population}

A total of 5 government primary schools was selected and all children who were present in the school during data collection were included in the study.

\section{Sample size determination}

The sample size for the prevalence of dental caries was calculated by using a single population proportion formula. The sample size for associated factors was determined using Epi info (version 7) at a confidence interval $(1-\alpha)=95 \%$ and power $(1-\beta)$ of $80 \%$. Finally, a $10 \%$ nonresponse rate was added to the calculated sample size. Therefore, the largest sample size, i.e. 422 was used for the study.

\section{Sampling}

A total of 422 children was included from 5 schools, out of the total 20 government primary schools in Harar town. The selection of school children for the study was detrmined as follows. First, the five primary schools were selected based on the lottery method. Secondly, ten sections from both the first cycle and second cycle level were selected by simple random sampling. Thirdly, students were distributed proportionally amongst each section. Finally, participants were selected based on the list from the class teacher's who is in - charge for the class using systematic random sampling. In the case of absenteeism and overlap, the next number was included in the study.

\section{Data collection}

A structured questionnaire was used to collect information about the socio-demographic characteristics and determinant factors relevant for dental caries amongst primary school children. Data were collected by face-toface interview with the help of the children's parents or guardians. Dietary data were collected using the Ethiopian demographic and health survey questionnaires as a baseline to estimate the habitual intake of foods and nutrients [16]. Interviewers collected information about the foods and drinks consumed during the preceding day by probing questions and cues that help the recollection of participant's memory. Two new versions were developed for this survey: version $\mathrm{C} 2$ for children aged 3-11 years designed for completion by a parent/guardian with help from the child, and version C3 for young people aged 12-17 years for completion by the young 
person with help from their parent/guardian. Both questionnaires list 15 foods or drinks with a measure defined for each item. Participants were asked to estimate the frequency and amount of each food or drink consumed per day.

\section{Clinical examination}

A trained dental therapist (nurse) and a dentist (doctor) with assistant data recorder performed the clinical examination in the classrooms. A dental visual examination was performed on each child by one examiner using a light-emitting diode (LED), dental mirror, and explorer. The diagnostic criteria for caries were followed according to the WHO recommendations [17]. The DMFT (decayed, missing, and filled tooth number) scores were recorded and dental decay is measured using the count of the number of teeth or surfaces in a child's that are decayed, missing or filled as a result of caries. A tooth was recorded as decayed when a lesion had an unmistakable cavity, undetermined enamel or detectably softened wall or floor. A tooth was recorded as missing when it was extracted due to caries. A tooth was recorded as filled when it was permanently filled without caries. The examiner was calibrated with an experienced dentist (doctor) in the same setting before the study. The intraexaminer agreement was assessed by re-examining a $10 \%$ random sample of the children on the same day. The dental assistant without the knowledge of the examiner performed the selection of children for duplicate examination.

\section{Specimen collection, culture, and identification}

Unstimulated whole saliva samples $(2 \mathrm{~mL})$ were collected from children [18] by a medical laboratory technologist. Children were requested to void saliva into a widemouthed disposable cup $2 \mathrm{~h}$ after their last meal in a mid-morning. The cup was then uniquely coded, kept in ice box, and transported for microbiological assay within $24 \mathrm{~h}$.

Saliva $(0.1 \mathrm{~mL})$ was diluted with normal saline $(0.9 \mathrm{~mL})$ and tenfold serial dilutions of saliva were made up to $10^{-6}$. The diluted sample $(100 \mu \mathrm{L})$ was spread [19] evenly onto de Man, Rogosa and Sharpe agar (MRS agar) (HI Media Laboratories Pvt. Ltd., India) to obtain direct counts of Lactobacilli. Plates were incubated anaerobically using the anaerobic candle jar system at $37^{\circ} \mathrm{C}$. After $48 \mathrm{~h}$ of incubation, plates were observed for the presence of Lactobacillus like colonies. Additionally, Gram staining or catalase test [19-21] was performed.

Colony counting was performed using a colony counter and the number of colony-forming units (CFU) was multiplied by the number of times the original milliliter of sample diluted (the dilution factor of the plate counted) and expressed as CFU/mL [19] of saliva. Besides, the determination of the salivary $\mathrm{pH}$ for each sample was performed, using a special $\mathrm{pH}$-test paper (Simplex Health $\mathrm{pH}$ test strips for urine and saliva: manufacturer part number sh003, United Kingdom). The threshold defined by the manufacturer made an interpretation.

\section{Data quality control}

A trained dental therapist performed clinical examination based on the WHO oral health assessment. Similarly, a trained medical laboratory technologist performed the laboratory diagnosis. A pretested and structured questionnaire used to collect data. The questionnaire was developed in the English language and translated to appropriate Ethiopian local languages (Amharic and Afan Oromo). Double entry was performed before data analysis for validation. Study participants were required to refrain from eating and drinking for a minimum of $2 \mathrm{~h}$ after arrival at school prior to sample collection.

Culture examinations were undertaken after checking growth-supporting characteristics, physical characteristics, gel strength and batch contamination of the media used. Prepared media quality was monitored by incubating $3-5 \%$ of the batch at $35-37^{\circ} \mathrm{C}$ for overnight. The reference strain of Lactobacillus casei (ATCC 393) and Lactobacillus fermentum (ATCC 9338) obtained from Ethiopia Public Health Institution (EPHI), Addis Ababa were used for quality control of culture.

\section{Data analysis}

Data were checked for completeness, cleared and then entered and validated by Epi data, software version 3.1 and exported to the Statistical Package for Social Science (SPSS) software version 25.0 for analysis. Odds ratios (OR) and their 95\% confidence intervals (CI) were estimated using bivariate and multivariate logistic regression analysis to identify possible explanatory variables on the occurrence of dental caries. The data were expressed as mean \pm SD. The $p$-value $<0.05$ was considered as statistically significant.

\section{Results \\ Socio-demographic characteristics of primary school children}

A total of 407 children was included in the study giving a response rate of $98 \%$. Of these, 214 (52.6\%) were boys and 193 (47.4\%) were girls. About 156 (38.3\%) and 251 (61.7\%) of the students were from the 1st cycle (grades 1-4) and 2nd cycle (grades 5-8), respectively. Most of the participants were Muslim (87.7\%). The Oromo (64.1\%), Harari (17.9\%) and Amhara (6.9\%) were amongst the study population. Nearly two-thirds (61.9\%) of the participants were living in an urban area (Table 1). 
Table 1 Socio-demographic characteristic of study participants amongst primary school children in Harar, Eastern Ethiopia, 2018

\begin{tabular}{|c|c|}
\hline Variables & Number (\%) \\
\hline \multicolumn{2}{|l|}{ Age in years } \\
\hline $6-11$ & $107(26.3)$ \\
\hline $12-15$ & $300(73.7)$ \\
\hline \multicolumn{2}{|l|}{ Sex } \\
\hline Boys & $214(52.6)$ \\
\hline Girls & $193(47.4)$ \\
\hline \multicolumn{2}{|l|}{ Grade } \\
\hline $1-4$ & $156(38.3)$ \\
\hline $5-8$ & $251(61.7)$ \\
\hline \multicolumn{2}{|l|}{ Residence } \\
\hline Urban & $252(61.9)$ \\
\hline Rural & $155(38.1)$ \\
\hline \multicolumn{2}{|l|}{ Ethnicity } \\
\hline Oromo & $261(64.1)$ \\
\hline Amhara & $28(6.9)$ \\
\hline Harari & $73(17.9)$ \\
\hline Gurage & $17(4.2)$ \\
\hline Somali & $8(2)$ \\
\hline Tigray & $2(0.5)$ \\
\hline Other & $18(4.4)$ \\
\hline \multicolumn{2}{|l|}{ Religion } \\
\hline Orthodox & $37(9.1)$ \\
\hline Muslim & $357(87.7)$ \\
\hline Protestant & $7(1.7)$ \\
\hline Catholic & $4(1)$ \\
\hline Other & $2(0.5)$ \\
\hline \multicolumn{2}{|c|}{ Average academic score (\%) } \\
\hline$<50$ & $24(5.9)$ \\
\hline$>50$ & $383(94.1)$ \\
\hline
\end{tabular}

Food consumption pattern, dietary habits and practices related to oral hygiene

In the case of children's dietary habits, it was found that $243(59.7 \%)$ had bread with tea for breakfast, 310 (76.2\%) drank up to $1500 \mathrm{~mL}$ of soft drinks per week and 358 (88\%) of them had taken various quantities of sweet foods on a daily basis. The mean salivary $\mathrm{pH}$ was found to be $6.5 \pm 1.1$. About $48.6 \%$ of the children showed acidic salivary $\mathrm{pH}$.

Of the total children, $36.9 \%$ did not clean their teeth at least once a day. However, the majority of second cycle students (71\%) had teeth cleaning habits of which $75.7 \%$ used a brush with toothpaste. About $48 \%$ of the children with dental caries neither had a tooth cleaning habit with a wooden stick nor with a toothbrush and $45.3 \%$ had no mouth rinsing habits after each meal (Table 2).
Table 2 Factors associated with dental caries amongst primary school children in Harar, Eastern Ethiopia, 2018

\begin{tabular}{|c|c|}
\hline Variables & Number (\%) \\
\hline \multicolumn{2}{|l|}{ Bread as a major staple food } \\
\hline Yes & $243(59.7)$ \\
\hline No & $164(40.3)$ \\
\hline \multicolumn{2}{|l|}{ Pasta as major staple food } \\
\hline Yes & $211(51.8)$ \\
\hline No & $196(48.2)$ \\
\hline \multicolumn{2}{|c|}{ Consumption of sugared tea (Daily) } \\
\hline Yes & $367(90.2)$ \\
\hline No & $40(9.8)$ \\
\hline \multicolumn{2}{|c|}{ Consumption of soft drinks (Daily) } \\
\hline Yes & $310(76.2)$ \\
\hline No & $97(23.8)$ \\
\hline \multicolumn{2}{|c|}{ Consumption of sweet foods (Daily) } \\
\hline Yes & $358(88.0)$ \\
\hline No & $49(12.0)$ \\
\hline \multicolumn{2}{|l|}{ Daily cleaning teeth } \\
\hline Yes & $257(63.1)$ \\
\hline No & $150(36.9)$ \\
\hline \multicolumn{2}{|l|}{ Way of cleaning teeth } \\
\hline Toothbrush with paste & $126(49.0)$ \\
\hline Tooth stick & $115(44.7)$ \\
\hline Toothbrush and tooth stick & $16(6.2)$ \\
\hline \multicolumn{2}{|c|}{ Rinse with water (After each meal) } \\
\hline Yes & $354(87.0)$ \\
\hline No & $53(13.0)$ \\
\hline \multicolumn{2}{|l|}{ Dental ache history } \\
\hline Yes & $148(36.4)$ \\
\hline No & $259(63.6)$ \\
\hline \multicolumn{2}{|c|}{ Treatment seeking places for dental ache } \\
\hline Health institution & $66(16.2)$ \\
\hline Pharmacy & $17(4.2)$ \\
\hline Traditional healer & $11(2.7)$ \\
\hline Nowhere & $313(76.9)$ \\
\hline \multicolumn{2}{|l|}{ Salivary pH } \\
\hline Acidic $(<6.5)$ & $198(48.6)$ \\
\hline Neutral (6.75-7.25) & $127(31.2)$ \\
\hline Basic (> 7.25) & $82(20.1)$ \\
\hline
\end{tabular}

\section{Prevalence of dental caries amongst primary school children}

About 150 (36.9\%) of the respondents had at least one carious tooth during examination (Fig. 1). Students from a rural setting had a nearly similar prevalence of caries with urban (38.1\% versus $36.3 \%)$. The occurrence of 


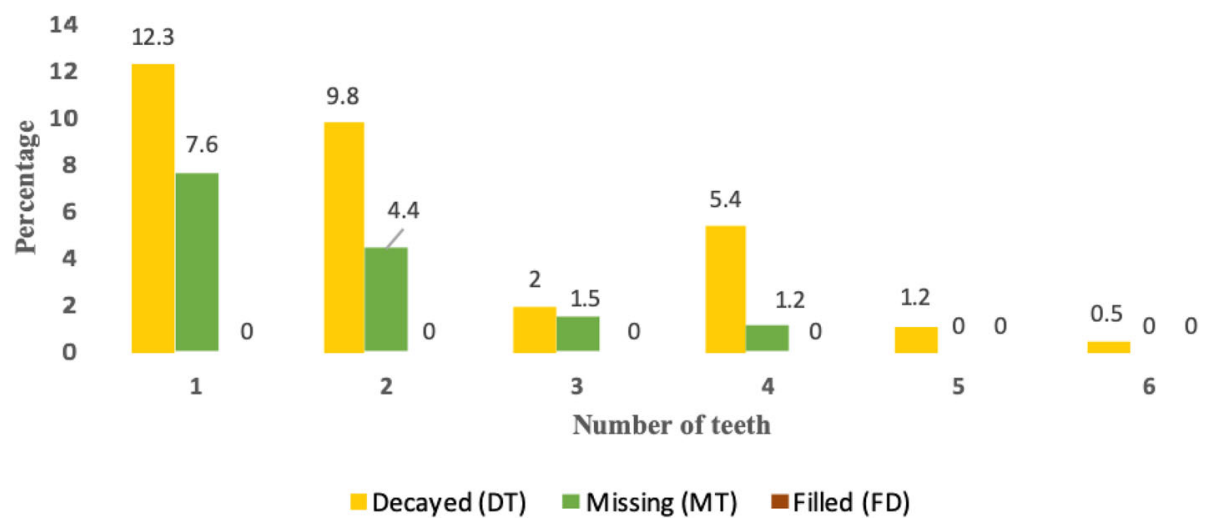

Fig. 1 Distribution of decayed, missing and filled teeth in primary school children in Harar, Eastern Ethiopia, 2018

dental caries was also similar between female (36.8\%) and male respondents (36.9\%). About $42.7 \%$ of the first cycle and $33.7 \%$ of second cycle students had caries. Amongst children with caries, $54.5 \%$ of them had previous year average academic scores less than $50 \%$ (Table 3).

\section{DMFT score of the primary school children}

The mean DMFT value of the participants was $0.95 \pm$ 1.57. The decayed teeth (DT) component had a mean value of $0.69 \pm 1.26$, contributing $84.6 \%$ to the DMFT value. The missing teeth (MT) contributed the rest, $15.4 \%$ (Table 4). Females had a DMFT score of $0.94 \pm$ 1.59 and males had $0.95 \pm 1.55$. Students from the Urban setting had a mean DMFT of $0.92 \pm 1.52$ compared to rural students with a mean DMFT of $0.99 \pm 1.66$. Second cycle students had less decayed and missing components compared to the first cycle students. Boys and girls had almost similar DMFT scores.

\section{Enumeration and identification of Lactobacillus spp. from saliva}

Significant Lactobacillus spp. count $\left(\geq 10^{5} \mathrm{CFU}\right)$ was identified in $67.1 \%$ of the saliva samples. The mean bacterial count was $14.92 \times 10^{5} \pm 22.92 \times 10^{5}$. A statistically significant association was found between caries and the salivary level of Lactobacillus spp. (AOR $=4.01 ; 95 \% \mathrm{CI}$ : 2.24-7.18; $p=<0.001$ )] (Table 3).

\section{Determinants of dental caries}

In the bivariate logistic regression analysis; age $(\mathrm{COR}=$ 1.49; $95 \%$ CI: $0.95-2.35 ; p=0.07)$, girls $(\mathrm{COR}=1.00,95 \%$ CI: $0.67-1.50 p=0.078)$, urban residency $(\mathrm{COR}=0.92$; 95\% CI: $0.60-1.39 ; p=0.075)$ were not statistically associated with dental caries. On the other hand, grade level $1-4(\mathrm{COR}=2.07$; 95\% CI: $1.37-3.14 ; p=0.001)$ and previous year average academic score less than $50 \%(\mathrm{COR}=$ 7.31; 95\% CI: $2.66-20.0 ; p=<0.001$ ) were found significant associations with dental caries.
In the rest bivariate logistic regression analysis; consumption of sweet foods $(\mathrm{COR}=2.5 ; 95 \% \mathrm{CI}: 1.21-5.17$; $p=0.002)$, absence of daily tooth cleaning habit $(\mathrm{COR}=$ 3.57; 95\% CI: 2.34-5.45; $p=0.002)$, absence of toothpaste use $(\mathrm{COR}=0.26 ; 95 \% \mathrm{CI}: 0.16-0.42 ; p=0.011)$, dental ache history $(\mathrm{COR}=3.03 ; 95 \% \mathrm{CI}: 1.99-4.62 ; p=$ 0.031), significant salivary Lactobacillus spp. count $(\mathrm{COR}=3.68 ; 95 \%$ CI: 2.24-6.04; $p=<0.001)$, and acidic salivary $\mathrm{pH}(\mathrm{COR}=2.87 ; 95 \% \mathrm{CI}: 1.75-4.72 ; p=0.001)$ of the children had significant association with dental caries (Table 3).

\section{Factors associated with dental caries amongst primary school children}

Variables with $p<0.25$ from the bivariate analysis were entered into multivariate analysis to control possible confounders and to identify determinant factors for dental caries. Variables with $p<0.05$ were considered statistically significant. On multivariate analysis grade levels of children, previous year average score, tooth cleaning habit, use of a toothbrush with paste, presence of toothache, salivary Lactobacillus spp. level, saliva with acidic $\mathrm{pH}$, and sweet food consumption habit remained significant predictors of dental caries. Besides, basic salivary $\mathrm{pH}$ was significantly associated with the model (Table 3 ).

There was a statistically significant difference in the development of dental caries based on the children's grade level. Children at grade level 1-4 were about 2 times more likely to develop dental caries than grade level $5-8 \quad(\mathrm{AOR}=1.73 ; 95 \% \mathrm{CI}=1.02-2.92)$. Primary school children who had dental caries were four times more likely to score $<50 \%$ average compared to children without dental caries (AOR $=3.68 ; 95 \% \mathrm{CI}=1.1-12.29$ ). Children who did not clean their teeth were 2 times more likely to have caries than those who cleaned $(\mathrm{AOR}=2.23 ; 95 \% \mathrm{CI}=1.32-3.78)$. Moreover, children who did not use a toothbrush with paste for cleaning their teeth were 3 times greater risk to have dental caries 
Table 3 Determinant factors of dental caries amongst primary school children in Harar, Eastern Ethiopia, 2018

\begin{tabular}{|c|c|c|c|c|c|}
\hline \multirow[t]{3}{*}{ Variables } & \multicolumn{2}{|c|}{ Dental caries } & \multirow[t]{3}{*}{ COR $(95 \% \mathrm{Cl})$} & \multirow[t]{3}{*}{ AOR $(95 \% \mathrm{Cl})$} & \multirow[t]{3}{*}{$P$-value } \\
\hline & Yes & No & & & \\
\hline & No. (\%) & No. (\%) & & & \\
\hline \multicolumn{6}{|l|}{ Grade } \\
\hline $1-4$ & $61(42.7)$ & $82(57.3)$ & $2.07(1.37-3.14)$ & $1.73(1.02-2.92)$ & 0.041 \\
\hline $5-8$ & 89(33.7) & 175(66.3) & 1 & 1 & \\
\hline \multicolumn{6}{|c|}{ Previous year average academic score (\%) } \\
\hline Less than 50 & $6(54.5)$ & $5(45.5)$ & $7.31(2.66-20.0)$ & $3.68(1.1-12.29)$ & 0.034 \\
\hline 50 and greater & $131(34.2)$ & $252(65.8)$ & 1 & 1 & \\
\hline \multicolumn{6}{|l|}{ Consumption of sweet foods } \\
\hline Yes & 140(39.2) & $217(60.8)$ & $2.5(1.21-5.17)$ & $4.08(1.62-10.2)$ & 0.003 \\
\hline No & $10(20.4)$ & 39(79.6) & 1 & 1 & \\
\hline \multicolumn{6}{|l|}{ Cleaning teeth } \\
\hline No & $72(48)$ & $78(52)$ & $3.57(2.34-5.45)$ & $2.23(1.32-3.78)$ & 0.002 \\
\hline Yes & $78(30.4)$ & 179(69.6) & 1 & 1 & \\
\hline \multicolumn{6}{|l|}{ Way of cleaning teeth } \\
\hline Toothbrush without paste & 97(39.4) & 149(60.6) & $0.26(0.16-0.42)$ & $3.05(1.69-5.49)$ & 0.001 \\
\hline Toothbrush with paste & $52(32.9)$ & $106(67.1)$ & 1 & 1 & \\
\hline \multicolumn{6}{|l|}{ Dental ache history } \\
\hline Yes & 79(53.4) & $69(46.6)$ & $3.03(1.99-4.62)$ & $2.95(1.78-4.89)$ & $<0.001$ \\
\hline No & $71(27.4)$ & 188(72.6) & 1 & 1 & \\
\hline \multicolumn{6}{|l|}{ Salivary Lactobacillus count } \\
\hline Significant & $125(45.8)$ & $148(54.2)$ & $3.68(2.24-6.04)$ & $4.01(2.24-7.18)$ & $<0.001$ \\
\hline Insignificant & $25(18.4)$ & 109(81.3) & 1 & 1 & \\
\hline \multicolumn{6}{|l|}{ Salivary pH } \\
\hline Acidic $(<6.5)$ & $58(42.9)$ & 113(57.1) & $2.87(1.75-4.72)$ & $1.93(1.07-3.48)$ & 0.028 \\
\hline Basic (> 7.25) & 27(32.9) & $55(67.1)$ & $0.83(0.41-1.69)$ & $0.38(0.17-0.88)$ & 0.025 \\
\hline Neutral (6.75-7.25) & $38(29.9)$ & $89(70.1)$ & 1 & 1 & \\
\hline
\end{tabular}

COR crude odds ratio, $A O R$ adjusted odds ratio, $C l$ confidence interval P-value $<0.05$

than those who did not $(\mathrm{AOR}=3.05 ; 95 \% \mathrm{CI}=1.69$ 5.49). The odds of having dental caries were significantly higher amongst children who suffered from toothache than those children who had not $(\mathrm{AOR}=2.95 ; 95 \% \mathrm{CI}=$ 1.78-4.89) (Table 3).

Children who had a significant count of salivary Lactobacillus spp. were 4 times more likely to have dental caries than those who had not $(\mathrm{AOR}=4.01 ; 95 \% \mathrm{CI}=$

Table 4 Components of DMFT score of primary school children in Harar, Eastern Ethiopia 2018

\begin{tabular}{lll}
\hline Variable & $\begin{array}{ll}\text { Component of DMFT Score } \\
\end{array}$ & \\
\hline X \pm SD & Percentage \\
\hline Decayed (DT) & $0.69( \pm 1.26)$ & 84.6 \\
Missing (MT) & $0.26( \pm 0.72)$ & 15.4 \\
Filled (FT) & 0 & 0 \\
DMFT & $0.95( \pm 1.57)$ & 100 \\
\hline
\end{tabular}

2.24-7.18). Similarly, children with acidic saliva $\mathrm{pH}$ were 2 times more prone to dental caries than children have a neutral saliva $\mathrm{pH}(\mathrm{AOR}=1.93 ; 95 \% \mathrm{CI}=1.07-3.48)$.

Children with sweet food consumption habit were 4 times more likely to develop dental caries than who had not ( $\mathrm{AOR}=4.08 ; 95 \% \mathrm{CI}=1.62-10.25$ ). In parallel, those who did not clean their teeth daily were 2 times more likely to develop dental caries compared to those who had a cleaning habit. Moreover, children who did not use toothpaste in cleaning their teeth were 1.3 times more risk to develop caries than children who used toothpaste. Also, those children who had experienced dental ache were 3 times more likely to have caries than those who had not (Table 3).

\section{Discussion}

In Ethiopia, there is a scarcity of data on dental caries amongst primary school children. Similarly, there is a 
lack of information on dental caries in Harar. This study revealed the prevalence of $36.9 \%$ dental caries amongst primary school children and found to be a common chronic health problem in Harar. The prevalence of dental caries found in the present study was higher than the prevalence in Bahir Dar (21.8\%) [1]. This study also similar to the caries prevalence reported from Gondar (36.3\%) [8]. However, it was lower than a study done in Addis Ababa (74\%) [22] and Finote Selam (48.5\%) [23]. In addition, our finding was lower than the studies conducted in Eritrea (78\%) [24], India (59\%) [25], and Qatar (85\%) [26].

This study revealed the mean DMFT (0.95) was much lower than the study done in Eritrea $(\mathrm{DMFT}=2.5)$ [24], Qatar $(\mathrm{DMFT}=4.62)[26]$ and India $(\mathrm{DMFT}=1.91)$ [25]. This DMFT value was also lower relative to the mean DMFT value stated by world oral health standards between the years of 2012-2013 [5]. To the contrary, the value was higher compared to the study done in Nigeria $(\mathrm{DMFT}=0.45) \quad[27]$ and Sudan $(\mathrm{DMFT}=0.42) \quad[28]$. From the comparisons of above differences might be due to the diversity in dietary habits and oral hygiene practices among stated country's communities and it might also be associated with various socio-economic and biologic risk factors [28]. The present study showed similarities to the study reported in Qatar [26] and Kenya [29] for the decay component as the primary contributor for the mean DMFT score.

Majority of the children with dental caries were able to score less $(<50 \%)$ in their previous year's cumulative score $(\mathrm{AOR}=3.68 ; 95 \% \mathrm{CI}: 1.10-12.29 ; p=0.034)$. This may be due to the impact of caries and associated infection that causes pain and discomfort leading to loss of attention and absence from school [9] which directly related to children's productivity [30, 31].

Children's grade level had a statistically significant association with dental caries. The 1st cycle (grades 1-4) students found to have 1.7 times more risk than the 2nd cycle (grades 5-8) students for dental caries. This study showed an increase in grade-level decreases the chance of dental caries. This finding was also consistent with the report from Bahir Dar showing that two times higher prevalence of dental caries amongst 1st cycle students [1]. The agreement with these findings might be because of better exposure to toothpaste by 2 nd cycle students.

Sweet food consumption has significantly associated with dental caries $(\mathrm{AOR}=4.08 ; 95 \% \mathrm{CI}: 1.62-10.25 ; p=$ 0.003). This finding was in agreement with the studies reported on the sugar intake as one of the predominant predictors of caries in Addis Ababa and Finote Selam $[22,23]$. The results agreement might be due to subsequent involvement of cariogenic bacteria produces copious acid by fermenting sugar in the sweet foods and leads to increased exposure of the enamel to decay [32, 33]. In consistent with the above statement, the present study revealed that Lactobacillus spp. count $\left(\geq 10^{5} \mathrm{CFU} / \mathrm{mL}\right)$ significantly associated with dental caries $(\mathrm{AOR}=4.01$; 95\% CI: 2.24-7.18; $p=<0.001)$. This finding relates to a study from Thailand $(p<0.001)$ [34] which reported high bacterial count as an indicator of high caries risk. Our finding contradicts with the study conducted in Romania $(p=0.131)$ [35] and the difference was due to different staple food and tooth cleaning habits.

Poor teeth cleaning habit was significantly associated with dental caries $(\mathrm{AOR}=2.23$; 95\% CI: $1.32-3.78$; $p=$ 0.002). The prevalence of dental caries was higher amongst the study participants who did not have daily teeth cleaning habits $(48 \%)$. It is a common fact that cleaning teeth removes away the food debris from the mouth. Therefore, Lactobacillus spp. and other cariogenic bacteria cannot get enough nutrients and time for growth [23, 32]. The present study reports that $40.9 \%$ of children cleaned their teeth using a traditional small wood stick (locally called mefakiya) for maintaining oral hygiene. Despite the type and nature of the traditional wood stick used in the study area, using these wood stick for teeth cleaning purposes could be the reason for the lower prevalence in the area relative to those areas with high prevalence [36].

Children who did not use the toothpaste were significantly associated with caries status in this study (AOR = 3.05; 95\% CI: $1.69-5.49 ; p=0.001$ ). The prevalence of dental caries was lower amongst those who cleaned their teeth using brush and toothpaste (32.9\%) than those who did not (39.4\%). The closeness between the above proportions was may be due to lack of knowledge on how to use a toothbrush amongst the users, which were consistent with the study reported in Addis Ababa which shows 52\% of children make bleed of their gum while brushing [22]. Although fluoride toothpaste is commercially available in the study area, the knowledge and the utilization of fluoride might have its own implication on the caries burden amongst toothpaste users and not users.

Dental ache is one of the common indicators of tooth decay [37]. In this study, children who had toothache were three times more likely to have dental caries $(\mathrm{AOR}=2.95 ; 95 \% \mathrm{CI}: 1.78-4.89 ; p=<0.001$ ). This finding was similar to the study conducted in Addis Ababa [22] and Sudan [28]. This might be due to the presence of a cavity before the history of pain [23]. Also, dental ache was stated as a prior reason to meet dentists [24].

\section{Limitations}

An important limitation of this study is that no causal inferences are allowed, since we used a cross-sectional study design. Besides, the comparatively small sample 
size for school children population limits generalizability of the findings.

\section{Conclusion}

The presence of significant salivary Lactobacillus spp. count $\left(\geq 10^{5} \mathrm{CFU} / \mathrm{mL}\right.$ ) associated with poor academic performance, being primary cycle students, sweet diet, poor teeth cleaning habit, dental ache history, and salivary $\mathrm{pH}$ were the determinant factors for the burden of dental caries.

Thus, dissemination of oral hygiene awarness and access to dental care services are assumed as supreme importance for the prevention of dental caries amongst primary school children in the study area.

\section{Abbreviations}

AOR: Adjusted odds ratio; ATCC: American Type Culture Collection; CFU: Colony forming unit; Cl: Confidence intervals; COR: Crude odds ratio; DMFT: Decayed, missing, filled tooth number; EPHI: Ethiopia Public Health Institution; IHRERC: Institutional Health Research Ethics Review Committee; MRS: Man Rogosa and Sharpe; OR: Odds ratios; SPSS: Statistical package for social science soft; WHO: World Health Organization

\section{Acknowledgments}

Our appreciation goes to the principal, teachers of primary schools, parents, and guardians of the children in Hara, Ethiopia.

\section{Authors' contributions}

DA, DA, and SB designed the research concept, methodology, data analysis, interpretation, and preparation of the manuscript for publication. DA carried out the laboratory work and sample collection. DA, DA, and SB critically reviewed and revised the manuscript. All authors read and approved the final manuscript.

\section{Funding}

The present study received no funding from any source.

\section{Availability of data and materials}

All necessary data supporting our findings can be found in the Haramaya University repository.

\section{Ethics approval and consent to participate}

The Haramaya University, College of Health and Medical Sciences Institutional Health Research Ethics Review Committee (IHRERC) approved this study. Informed, voluntary, written and signed consent from parents/ guardians and principals of the concerned schools with assent from participants was obtained. The subjects received an oral examination and referral for treatment as appropriate and upon completion of the dental examination and the interview, health education about oral health was given to the study subjects. The treatment cost to those parents/guardians who can afford the treatment fee was covered by themselves, but for those who cannot afford; the principal investigator covered it. Participants' confidentiality of information was assured by excluding names and identifiers in the questionnaire.

\section{Consent for publication}

In our study, we don't have any images or videos, etc. of individual participants.

\section{Competing interests}

The authors declare that there is no financial or non-financial competing interests from anybody or institute. We also want to assure that we did not receive any technical assistance in developing the research concept or preparation of the manuscript.

\section{Author details}

'Department of Medical Laboratory Sciences, College of Health and Medical Sciences, Haramaya University, P.O. Box: 235, Harar, Ethiopia. ${ }^{2}$ Department of Medical Microbiology, College of Health and Medical Sciences, Haramaya University, P.O. Box: 235, Harar, Ethiopia.

Received: 3 April 2019 Accepted: 9 January 2020

Published online: 16 January 2020

\section{References}

1. Mulu W, Demilie T, Yimer M, Meshesha K, Abera B. Dental caries and associated factors among primary school children in Bahir Dar city: a crosssectional study. BMC Res Notes. 2014;7:949.

2. World Health Organization. Oral Health. [Online].; 2017 [cited 2019 August 20. Available from: https://www.who.int/oral_health/disease_ burden/global/en/.

3. Dimaisip-Nabuab J, Duijster D, Benzian H, Heinrich-Weltzien R, Homsavath A, Monse B, Sithan H, Stauf N, Susilawati S, Kromeyer-Hauschild K. Nutritional status, dental caries and tooth eruption in children: a longitudinal study in Cambodia, Indonesia and Lao PDRBMC Pediatr 2018; 18(1): 300

4. World Dental Federation. The Oral Health Atlas. $2^{\text {nd }}$ ed. FDI, editor. Brighton: Myriad Editions; 2015.

5. World Health Organization. WHO methods and data sources for global burden of disease estimates 2000-2015. Geneva: Department of Information, Evidence, and Research; 2017.

6. RCdo A, Batista MJ, MPMR M, Cypriano S, MdaLR S. Dental caries trends among preschool children in Indaiatuba, SP, Brazil. Braz J Oral Sci. 2014; 13(1):1-5.

7. Hoceini A, Khelil N, Ben-Yelles I, Mesli A, Ziouani S, Ghellai L, Aissaoui N, Nas F, Arab M. Caries-related factors and bacterial composition of supragingival plaques in caries free and caries active Algerian adults. Asian Pac J Trop Biomed. 2016:6(8):720-6.

8. Ayele FA, Taye BW, Ayele TA, Gelaye KA. Predictors of dental caries among children 7-14 years old in Northwest Ethiopia: a community based crosssectional study. BMC Oral Health. 2013;13(1):7

9. Fung MHT, Wong MCM, Lo ECM, Chu CH. Early childhood caries: a literature review. J Oral Hyg Health. 2013;1:107.

10. Lee MO, Lee EJ. Effects of adolescent and Oral health-related characteristics on dental caries. Korean J Health Serv Manag. 2018;12(2):101-12.

11. Kotha SB, AlFaraj NSM, Ramdan TH, Alsalam MA, Al Ameer MJ, Almuzin ZM. Associations between diet, dietary and oral hygiene habits with caries occurrence and severity in children with autism at Dammam City, Saudi Arabia. Open Access Maced J Med Sci. 2018;6(6):1104-10.

12. Hujoel PP, Hujoel ML, Kotsakis GA. Personal oral hygiene and dental caries: a systematic review of randomised controlled trials. Gerodontology. 2018; 35(4):282-9

13. Hans R, Thomas S, Garla B, Dagli R, Hans M. Effect of various sugary beverages on salivary $\mathrm{pH}$, flow rate, and oral clearance rate amongst adults. Scientifica. 2016;2016:5027283.

14. Karabekiroğlu S, Ünlü N. Effectiveness of different preventive programs in cariogram parameters of young adults at high caries risk. Intl J Dent. 2017; 2017:7189270.

15. Center for Disease Control and Prevention. School-Based Dental Sealant Programs. [Online].; 2016 [cited 2017 November 3. "https://www.cdc.gov/ oralhealth/dental_sealant_program/index.htm".

16. Central Statistical Agency (CSA) [Ethiopia] and ICF. Ethiopia Demographic and Health Survey 2016. Addis Ababa, and Rockville, Maryland: CSA and ICF; 2016

17. World Health Organization. Oral health surveys basic methods. 5th ed. Geneva: WHO library cataloging-in-publication data; 2013.

18. Henson BS, Wong DT. Collection, storage, and processing of saliva samples for downstream molecular applications. Methods Mol Biol. 2010;666:21-30.

19. Senthilkumar B, Zothansanga, Senbagam D, Senthilkumar N, Gurusubramaniam G. Practical Microbiology - A Laboratory Manual. 1st ed. New Delhi: Panima Publishing Corporation; 2014. https://doi.org/10.13140/2. 1.2667.6163.

20. Ahirwar SS, Gupta MK, Gupta G, Singh V. Screening, isolation and identification of Lactobacillus species from dental caries of children. Int J Curr Microbiol App Sci. 2017;6(1):497-503. 
21. Nithya K, Senbagam D, Senthilkumar B, Udhayashree N, Gurusamy R. Characterization of bacteriocin producing lactic acid bacteria and its application as a food preservative. Afr J Microbiol Res. 2012;6(6):1138-46.

22. Burnett $D$, Aronson J, Asgary R. Oral health status, knowledge, attitudes, and behaviors among marginalized children in Addis Ababa, Ethiopia. J Child Health Care. 2016;20(2):252-61.

23. Teshome A, Yitayeh A, Gizachew M. Prevalence of dental caries and associated factors among Finote Selam primary school students aged 12-20 years, Finote Selam town, Ethiopia. OHDM. 2016;15:36-41.

24. Andegiorgish AK, Weldemariam BW, Kifle MM, Mebrahtu FM, Zewde HK, Tewelde MG, Hussen MH, Tsegay WK. Prevalence of dental caries and associated factors among 12 years old students in Eritrea. BMC Oral Health. 2017;17(1):169.

25. Fergus CE. Caries prevalence and experience of 12-year old children in Montserrat. West Indian Med J. 2010;59(5):573-7.

26. Al-Darwish M, El Ansari W, Bener A. Prevalence of dental caries among 1214-year-old children in Qatar. Saudi Dent J. 2014;26(3):115-25.

27. Sofola OO, Folayan MO, Oginni AB. Changes in the prevalence of dental caries in primary school children in Lagos state, Nigeria. Niger I Clin Pract. 2014;17(2):127-33.

28. Tagelsir A, Khogli AE, Nurelhuda NM. Oral health of visually impaired schoolchildren in Khartoum state, Sudan. BMC Oral Health. 2013;13(1):33.

29. Fukuda H, Ogada CN, Kihara E, Wagaiyu EG, Hayashi Y. Oral health status among 12-year-old children in a rural Kenyan community. J Dent Oral Health. 2014;1:1-5.

30. Jackson SL, Vann WF Jr, Kotch JB, Pahel BT, Lee JY. Impact of poor oral health on children's school attendance and performance. Am J Public Health. 2011;101(10):1900-6.

31. Sachdev J, Bansal K, Chopra R. Effect of comprehensive dental rehabilitation on growth parameters in pediatric patients with severe early childhood caries. Intl J Clin Pediatr dent. 2016;9(1):15.

32. Dawani N, Nisar N, Khan N, Syed S, Tanweer N. Prevalence and factors related to dental caries among pre-school children of sadder town, Karachi, Pakistan: a cross-sectional study. BMC Oral Health. 2012;12:59.

33. Sheiham A, James WP. Diet and dental caries: the pivotal role of free sugars reemphasized. J Dent Res. 2015;94(10):1341-7.

34. Piwat S, Teanpaisan R, Thitasomakul A, Thearmontree A, Dahlen G. Lactobacillus species and genotypes associated with dental caries in Thai preschool children. Mol Oral Microbiol. 2010;25(2):157-64.

35. Eşian D, Man A, Burlibasa L, Burlibasa M, Perieanu MV, Bică Cl. Salivary level of Streptococcus mutans and Lactobacillus spp. related to a high risk of caries disease. Rom Biotechnol Lett. 2017;22(2):12496-503.

36. Bairwa R, Gupta P, Gupta VK, Srivastava B. Traditional medicinal plants: use in oral hygiene. Int J Pharm Chem Sci. 2012;1 (4):1529-38.

37. Maro D, Roberst H, Machibya F, Kahabuka K, Mugonzibwa EA. Previous toothache, dental visits and caries presence among primary school children in dares Salam. Tanz Dent J. 2012;17(2):50-5.

\section{Publisher's Note}

Springer Nature remains neutral with regard to jurisdictional claims in published maps and institutional affiliations.

Ready to submit your research? Choose BMC and benefit from:

- fast, convenient online submission

- thorough peer review by experienced researchers in your field

- rapid publication on acceptance

- support for research data, including large and complex data types

- gold Open Access which fosters wider collaboration and increased citations

- maximum visibility for your research: over $100 \mathrm{M}$ website views per year

At $\mathrm{BMC}$, research is always in progress.

Learn more biomedcentral.com/submissions 